\title{
Análisis comparativo de la virtud de la sabiduría propuesta por la psicología positiva en relación a la propuesta aristotélica.
}

\section{Comparative analysis of the virtue of wisdom proposed by positive psychology in relation to the Aristotelian proposal.}

DOI: 10.32870/sincronia.axxv.n80.3b21

\author{
Rómulo Ramírez Daza y García \\ Departamento De Humanidades. Universidad Panamericana, Campus Guadalajara. (MÉXICO) \\ CE: rramirez@up.edu.mx / ID ORCID: 0000-0001-7280-3812
}

\section{Enrique Salvador López Fernández}

Escuela de Pedagogía. Universidad Panamericana, Campus Guadalajara. (MÉXICO)

CE: enrique.lopez@up.edu.mx

Esta obra está bajo una Licencia Creative Commons Atribución-NoComercial 4.0 Internacional

Recibido: $10 / 02 / 2021$

Revisado: 30/04/2021

Aprobado: 16/06/2021

\section{RESUMEN}

En términos de transdisciplinariedad se confrontará el contraste entre la psicología positiva de Seligman y la teoría de las virtudes de Aristóteles, ya que ambas tienden a rescatar el núcleo central de la conformación del ser humano, que son las virtudes o fortalezas del capital humano. Se abordará vía una hermenéutica comparada la confluencia que esta teoría contemporánea tiene con la visión eudemonista aristotélica, ya que la sumatoria de virtudes entendidas como una segunda naturaleza -construida por buenos hábitos- es una aportación originaria del filósofo griego. El percatarnos de dicho encuentro confluyente o arista convergente desde un punto de vista analítico, como denominador común en ambas teorías, permite hacer una conexión de historicidad que muchas veces se elide en el pensamiento contemporáneo por desconocimiento. 
Palabras clave: Aristóteles. Ética eudemonista. Psicología positiva. Vida buena. Seligman. Virtudes intelectuales.

\section{ABSTRACT}

In terms of transdisciplinarity, the contrast between Seligman's positive psychology and Aristotle's theory of virtues will be confronted, since both tend to rescue the central nucleus of the formation of the human being, which are the virtues or strengths of human capital. The confluence that this contemporary theory has with the Aristotelian eudemonist vision will be approached via a comparative hermeneutic, since the summation of virtues understood as second nature -built by good habits- is an original contribution of the Greek philosopher. Noticing this confluent meeting or convergent edge from an analytical point of view, as a common denominator in both theories, allows us to make a connection of historicity that is often eluded in contemporary thought due to ignorance.

Keywords: Aristotle. Eudemonist ethics. Positive psychology. Good life. Seligman. Intelectual virtues.

El presente artículo, busca presentar y comparar la visión que sobre la virtud de la sabiduría tienen por su parte la Psicología positiva y la filosofía realista aristotélica. La primera argumenta desde una postura psicológica y la segunda desde una postura filosófico-antropológica de corte realista. Aunque son dos disciplinas, visiones y épocas distintas, la relación o cercanía está en el objeto de estudio: la sabiduría. En nuestro contexto actual, prácticamente no se habla de sabiduría, pero ciertamente está implicada en nuestras prácticas.

La filosofía realista como modelo filosófico griego, tiene un mayor bagaje en el conocimiento de esta virtud, porque la viene madurando desde mucho tiempo atrás; además de que "todos los sistemas éticos clásicos, desde Platón y Aristóteles, son sistemas de virtudes" (Valenzuela, 2014, p. 23). En el caso de la Psicología positiva, la cual es una corriente psicológica de relativo reciente nacimiento, su bagaje le viene de la misma filosofía, de la psicología profunda y lo que ella misma por sus propias investigaciones ha hecho referente a la manifestación de esta virtud en el hombre.

El objetivo final de este artículo será determinar qué tanto la visión de la Psicología positiva sobre la virtud de la sabiduría empata con la propuesta por la filosofía realista. Para ello, 
analizaremos las dos propuestas que luego confrontaremos en el ánimo de clarificar su concepto lo mejor posible, y ver lo aprovechable de ambas.

Desde el inicio de sus investigaciones y escritos, alrededor de la década de 1980, la Psicología positiva ha tenido entre sus objetivos fundamentales el investigar, definir y desarrollar programas para "aumentar [y reforzar] las fortalezas y las virtudes y ofrecer pautas para encontrar lo que Aristóteles denominó la "buena vida'" (Seligman, 2002, p. 12). A partir de esta inquietud se han alentado una serie de investigaciones y estudios que tienen el propósito de promover el desarrollo de una clasificación psicológico-operacional de las virtudes y las fortalezas del carácter, que permita: identificarlas, medirlas, cultivarlas e impulsarlas, pues "la dimensión moral y ética del ser humano comprende toda la vida práctica, todas las acciones humanas" (Valenzuela, 2014, p. 24). Para la Psicología positiva, estas virtudes y fortalezas del carácter, según se manifiesten, confieren una determinada calidad de la existencia humana. Es decir, las virtudes y las fortalezas de carácter contribuyen a la realización plena de las personas (Seligman, et al., 2005).

Retomando las ideas referentes a la 'vida buena' definida por Aristóteles en su Ética a Nicómaco (en adelante se abreviará como EN), la Psicología positiva busca definir y explicar las virtudes. Apoyándose en las ideas de la ética aristotélica, trata de explicar y clasificar las virtudes y fortalezas que promueve para alcanzar la vida buena y la vida significativa (Lee, A., Steen, T. \& Seligman, M., 2005); (Seligman, M., 2002). Entendiendo la 'vida buena' como la identificación y puesta en práctica de las características positivas personales; es decir, la utilización de las fortalezas de carácter y las virtudes en proyectos específicos, "Una vida construida alrededor de esas características se acerca a lo que Aristóteles llamó ‘eudaimonía' o 'la buena vida'” (Lee, A., Steen, T. \& Seligman, M., 2005, p. 635). Por otro lado, la 'vida significativa' se entiende como el comprometerse con las propias fortalezas y virtudes, involucrándose en lo que la Psicología positiva llama instituciones positivas: aquellas que facilitan el perfeccionamiento de la persona. Ejemplo de ellas pueden ser la familia, la democracia, la religión, entre otras.

Hablando sobre las fortalezas de carácter, las emociones positivas y su puesta en práctica en instituciones, Lee, Steen y Seligman (2005) señalan lo siguiente: 
Creemos que las características y las emociones positivas florecen en el contexto de las instituciones positivas. Como el significado se deriva de la pertenencia y el servicio a algo mayor que uno mismo, una vida llevada en el servicio de instituciones positivas es una vida significativa". (pp. 635-636).

Sobre esto mismo, Seligman (2002, p. 382), argumenta que para alcanzar una vida significativa es necesario dirigir las fortalezas y virtudes personales hacia objetivos y acciones que nos trasciendan, utilizándolas al servicio de algo más elevado que nosotros mismos.

Antes de presentar la descripción que la Psicología positiva hace de las virtudes y en particular de la virtud de la sabiduría, hagamos una breve revisión de la ética aristotélica, para después, en un segundo momento, revisar la propuesta de la Psicología positiva. En un tercer momento final, haremos la comparación respectiva entre las dos posturas con el fin de poder determinar la cercanía o lejanía entre las dos, una clásica filosófica y otra psicológica. Seguimos aquí aquel principio aristotélico de que 'de la contrastación nace la luz'.

\section{Las virtudes en la Ética a Nicómaco o El tratamiento aristotélico de las virtudes}

Aristóteles expone su teoría de las virtudes en varias obras: Ética Eudemia, Ética a Nicómaco, y Magna Moral. La primera parece ser una obra de juventud de su periodo platónico, mientras que la tercera parece ser un compedio posterior y un tanto incompleto de la materia, aparecido a la muerte del filósofo. Además, desde el punto de vista sistemático, es la Ética a Nicómaco la mejor escrita, la más armónica y de las tres la más madura en sus tesis expuestas. Razón por la cual en esta investigación nos centraremos en la Nicomaquea siguiendo este criterio filológico.

En concreto, traigamos a colación lo que para Aristóteles es 'el bien', 'la felicidad' o 'eudaimonía' y la 'virtud'. Para Aristóteles (1996) el bien es "aquello a que todas las cosas aspiran" $(E N I, 1)$, y es en las virtudes que se concentra ese bien. Hablando sobre las acciones, las artes y las ciencias, afirma que: "siendo como son en gran número las acciones, las artes y ciencias, muchos serán de consiguiente los fines" (EN I, 1). Relacionando lo anterior con el bien, en EN I 2, Aristóteles 
(1996) escribe: "si existe un fin de nuestros actos querido por sí mismo, y los demás por él; y si es verdad también que no siempre elegimos una cosa en vista de otra [...], es claro que ese fin último será entonces no sólo el bien, sino el bien soberano" (EN I, 2).

En estos textos de Aristóteles podemos ver cómo para él, el bien es el fin de las cosas humanas, ya se trate de una acción ?teórico o práctica? o de una producción, de aquí se infieren los tres tipos de acción en Aristóteles: theoría, praxis y poíesis. Que hay una escala o jerarquía de bienes, en donde lo inferior está supeditado a lo superior, lo secundario a lo primario, y el efecto a la causa; y, que hay un bien último o supremo al que todos los hombres aspiran por encima de otros bienes. A este fin último o supremo Aristóteles lo llamó felicidad o 'eudaimonía' (que los traductores actuales prefieren emplear el término 'florecimiento'), el cual no es un fin concreto, sino un fin genérico que alienta a los fines concretos para ser alcanzado como fin último sumando todos los fines intermedios. O sea que, para alcanzar la 'eudaimonía' hay que acumular en cantidad y en calidad muchos fines buenos de virtudes singulares o particulares.

La lógica de las virtudes hace que éstas se superpongan y se ayuden unas a otras por así decirlo, para fortalecer más la acción del sujeto. Esto hace que una persona que tiene varias virtudes es más fácil que obtenga otras que aún no posee, y que le sea difícil caer en el vicio, o por lo menos que le sea más difícil fallar moralmente dado que tiene en su acervo muchos recursos a diferencia de quien no los tiene. Y visceversa, es más proclive al vicio alguien que tiene ya otros vicios; el resultado es que se aleja de ese fin que es el bien, y se ve frustrado su intento por ser feliz.

Se podría afirmar entonces que, desde la visión aristotélica, el bien (tò agathós) es entendido como aquello a lo que todos aspiramos, y a su vez, este bien general expresado en bienes particulares se dividen en bienes concretos que dan por sumatoria el bien genérico, supremo, soberano, perfecto o último, que será lo que conocemos como felicidad como acabamos de explicar anteriormente. La 'felicidad' o 'eudaimonía', por lo tanto, es un anhelo lejano por el que hay que esforzarse por alcanzar; es decir, "la actividad más perfecta, la más elevada y excelente, la más bella [...] lo bueno por sí mismo [...] la vida conforme a la razón o vida virtuosa" (Rodríguez, 2010, p. 116). 
Y, por lo tanto, la virtud será la perfección de la actividad humana según la razón. En otras palabras, vivir buscando la virtud o tratar de vivir virtuosamente será vivir buscando la felicidad.

Si profundizamos en esta visión ética de Aristóteles sobre la felicidad, advertimos que es una concepción basada en la fuerza de las virtudes, que sumadas unas a otras en la personalidad y acciones de una persona, nos proponen una moral basada en buenos hábitos que se vuelven al cabo una segunda naturaleza en los individuos que los poseen. Recordemos que las virtudes son definidas por Aristóteles como buenos hábitos (héxis), obtenidos mediante el esfuerzo y la repetición de un mismo tipo de acciones que acaban configurando lo que hoy llamaríamos 'la personalidad' o el éthos de una persona.

\section{La virtud de la sabiduría en la EN de Aristóteles}

Según la EN (1996) la sabiduría puede abordarse referido a lo más consumado en cada arte o saber, o bien como "el más riguroso saber entre todos, de suerte que la sabiduría será a la par intuición y ciencia, como si fuese la ciencia de las cosas más altas y cabeza de todo saber" (EN VI, 7). Pero esta visión en el pensamiento aristotélico no es precisamente un saber abocado a la práctica, sino es a través de la virtud de la prudencia 'phrónesis' que es la que guía al hombre hacia el bien, a la justicia y a la belleza (Valenzuela, 2014, pp. 34-51).

La sabiduría sin embargo juega un rol de virtud guía en todas las dimensiones del proceder humano; en efecto, "la sabiduría es ciencia e intuición de las cosas más ilustres por naturaleza, y son sabios los que saben de cosas superiores y maravillosas y arduas y divinas" (EN VI, 7). Y cuando se trata de aplicar los conocimientos teóricos a una práctica en los terrenos de la acción humana, el concurso de virtudes a través de la prudencia se hace presente en la ocasión que lo amerite, o mejor dicho, la virtud que salga al frente será la que la situación concreta requiera.

Para Aristóteles hay dos tipos de virtudes que operan en sincronía y armonía: las virtudes éticas y las virtudes dianoéticas, las primeras son las propiamente prácticas o morales, mientras que las segundas son las propias de la mente y del conocimiento ('dianoia'). Unas perfeccionan la acción 
práctica y las otras la acción pensante, por lo que no son excluyentes sino muy por el contrario, complementarias (Gómez-Robledo, 2001, pp. 319-347).

Y es que la sabiduría está a la cabeza de este modelo del saber práctico aristotélico ya que “quien posee en grado máximo la ciencia de lo universal, conoce en cierto modo, por lo menos virtualmente, todos los casos particulares que caen bajo el universal" (Gómez-Robledo, 2001, p. 379). Y la prueba de ello es que, si hacemos una relectura retroproyectiva hacia adelante, veremos que todas las veinticuatro virtudes que la Psicología positiva propone, Aristóteles las considera en diferentes partes de su corpus ethicum. Podríamos resumir quizás toda la concepción aristotélica en un fragmento de Heráclito, que está expresado aforísticamente: “La sabiduría es una sola: conocer la razón, por la cual todas las cosas son dirigidas por todas" (Farre, 1982, p. 119). En suma, para Aristóteles:

[...] la sabiduría es el mejor de los modos de conocer [...] es intelección y ciencia de lo más excelente por naturaleza. Por consiguiente, tanto por su modo de saber como por su objeto, la sabiduría es el tipo de conocimiento que Aristóteles instituye como propiamente filosófico. (Montoya \& Conill, 1988, p. 35).

Así, si comparamos la propuesta del siguiente cuadro (Seligman et al., 2005), y su equivalente de las virtudes en Aristóteles. Tenemos las siguientes correspondencias:

\begin{tabular}{|c|c|c|}
\hline VIRTUD & SELIGMAN & CORRESPONDENCIAS EN ARISTÓTELES \\
\hline \multirow{5}{*}{$\begin{array}{l}\text { 1. Sabiduría } \\
\text { Fortalezas cognitivas } \\
\text { que implican la } \\
\text { adquisición y el uso del } \\
\text { conocimiento }\end{array}$} & 1. Creatividad & $\begin{array}{l}\text { El impulso creativo de la póiesis hace la generación de todas las } \\
\text { artes. }\end{array}$ \\
\hline & 2. Curiosidad & $\begin{array}{l}\text { La scholé es el impulso de búsqueda inicial y el principio del } \\
\text { filosofar. }\end{array}$ \\
\hline & 3. Juicio o Mente abierta & El krinéin o buen juicio permite anticiparse a la toma de decisiones \\
\hline & 4. Amor al aprendizaje & La philos (amor) sophia (verdad) es el motivo principal de la investigación \\
\hline & 5. Perspectiva & El buen consejo es un tópos o lugar común del actuar prudencial \\
\hline \multirow{3}{*}{$\begin{array}{l}\text { 2. Valentía } \\
\text { Fortalezas que implican } \\
\text { el ejercicio de la } \\
\text { voluntad para lograr } \\
\text { metas a pesar de la }\end{array}$} & 6. Valor o Valentía & $\begin{array}{l}\text { Es la andréia griega que nos templa para continuar en la vida y } \\
\text { afrontar peligros o dolores }\end{array}$ \\
\hline & $\begin{array}{l}\text { 7. Honestidad, Autenticidad o } \\
\text { Integridad }\end{array}$ & $\begin{array}{l}\text { Hablar con la verdad, presentarse de manera genuina y tener } \\
\text { coherencia moral y vital }\end{array}$ \\
\hline & 8. Perseverancia o Persistencia & $\begin{array}{l}\text { Mantenerse en los ideales trazados y no desistir ante las } \\
\text { dificultades }\end{array}$ \\
\hline
\end{tabular}




\begin{tabular}{|c|c|c|}
\hline oposición & 9. Entusiasmo o Vitalidad & $\begin{array}{l}\text { Tener confianza en el orden racional del cosmos y ser partícipe de } \\
\text { la luz del ser }\end{array}$ \\
\hline \multirow{3}{*}{$\begin{array}{l}\text { 3. Humanitarismo } \\
\text { Fortalezas } \\
\text { interpersonales }\end{array}$} & 10. Amor & $\begin{array}{l}\text { El valor de la philia en todas sus especies nos capacita mejor para } \\
\text { las relaciones sociales al interior de la pólis. }\end{array}$ \\
\hline & 11. Bondad, Amabilidad o Generosidad & $\begin{array}{l}\text { La magnanimidad (megalopsichía), el ser amable y el ser } \\
\text { benefactor de otros nos retribuye un alma más generosa }\end{array}$ \\
\hline & 12. Inteligencia social & La empatía nos capacita a tener mejores relaciones \\
\hline \multirow{3}{*}{$\begin{array}{l}\text { 4. Justicia } \\
\text { Fortalezas cívicas que } \\
\text { subyacen una vida } \\
\text { comunitaria saludable }\end{array}$} & 13. Trabajo en equipo & $\begin{array}{l}\text { El hombre es por naturaleza un animal gregario que necesita de } \\
\text { los demás para poder realizarse }\end{array}$ \\
\hline & 14. Equidad o Responsabilidad social & $\begin{array}{l}\text { La justicia equitativa entre iguales y el responder a nuestros seres } \\
\text { queridos }\end{array}$ \\
\hline & 15. Liderazgo & Hay señores por naturaleza con altas dotes de mando \\
\hline \multirow{4}{*}{$\begin{array}{l}\text { 5. Templanza } \\
\text { Fortalezas que } \\
\text { protegen contra los } \\
\text { excesos }\end{array}$} & 16. Perdón, Misericordia o Compasión & Perdonar a nuestros seres queridos por las ofensas recibidas \\
\hline & 17. Humildad o Modestia & Rehuir la vanagloria y abrazar la modestia \\
\hline & 18. Autorregulación o Autocontrol & Dominio de sí, continencia \\
\hline & 19. Prudencia & Phrónesis, deliberar antes de actuar \\
\hline \multirow{5}{*}{$\begin{array}{l}\text { 6. Trascendencia } \\
\text { Fortalezas que forjan } \\
\text { conexiones con un } \\
\text { universo mayor, que } \\
\text { dan sentido }\end{array}$} & $\begin{array}{l}\text { 20. Apreciación de la belleza y la } \\
\text { excelencia }\end{array}$ & Kalokaghatía, Amar la belleza y la bondad en las acciones \\
\hline & 21. Gratitud & Retribuir con finezas a nuestros deudos \\
\hline & 22. Esperanza u Optimismo & Esperar lo mejor después del empeño en el trabajo \\
\hline & 23. Humor o Alegría & Eutrapelia, capacidad de ser alegre y jugar con los niños \\
\hline & 24. Espiritualidad o Religiosidad & Respetar las creencias religiosas de la ciudad \\
\hline
\end{tabular}

Cuadro 1: Las virtudes con sus fortalezas. Retomado y adaptado de Seligman (2005); la parte de Aristóteles es nuestra.

\section{Las virtudes en la Psicología positiva}

Veamos ahora la propuesta de la Psicología positiva sobre las virtudes humanas. Para esta corriente psicológica las virtudes son entendidas como características positivas psicológicas y de comportamiento de la persona, las cuales son bien valoradas por grandes pensadores y filósofos morales, así como por un gran número de sujetos en distintas culturas y momentos de la historia (Carr, 2007). Confirmando lo anterior, para Powelski (2003), Peterson \& Seligman (2004) y Seligman et al. (2005), las virtudes se pueden concebir como aquellos rasgos o características positivas que diferencian a las personas, son valiosas para casi todas las culturas del mundo en todos los tiempos, y a su vez están conformadas por una serie de fortalezas particulares.

Las virtudes que la Psicología positiva y en particular Peterson \& Seligman (2004) designan, hasta este momento, según reportan las investigaciones realizadas $\neg-$ como las seis que conforman el carácter, las siguientes: 1. sabiduría o conocimiento, 2. valentía, 3. humanitarismo, 4. equidad, 5. 
templanza y 6. trascendencia. ¿Por qué éstas y no otras? Estas virtudes fueron las que, después de una larga investigación (Seligman, 2002); (Powelski, 2003); (Peterson \& Seligman, 2004); (Seligman et al., 2005); (Carr, 2007), se repitieron o fueron comunes en casi todas las tradiciones sociales, culturas del mundo, épocas de la humanidad y escritos de diferentes filósofos y pensadores morales. Estas virtudes son así el común denominador de tradiciones pensantes y de historia de las ideas. Dichas virtudes se pueden describir de la siguiente forma:

1. La Sabiduría o conocimiento. Esta virtud integra las fortalezas que ayudan a la consecución y al uso de los diferentes saberes (Peterson \& Seligman, 2004; Seligman et al., 2005 y Carr, 2007).

2. La Valentía. Se refiere a las fortalezas que permiten poner en práctica la voluntad para alcanzar una meta sobrepasando diferentes obstáculos, ya sean intrínsecos o extrínsecos (Peterson \& Seligman, 2004; Seligman et al., 2005 y Carr, 2007).

3. El Humanitarismo. Implica la puesta en práctica de las fortalezas que ayudan a tener buenas o positivas relaciones interpersonales (Peterson \& Seligman, 2004; Seligman et al., 2005 y Carr, 2007).

4. La Justicia. En esta virtud se manifiestan las fortalezas cívicas que ayudan a tener una vida buena en comunidad (Peterson \& Seligman, 2004; Seligman et al., 2005 y Carr, 2007).

5. La Templanza. En ella se integran las fortalezas de carácter que protegen contra los excesos (Peterson \& Seligman, 2004; Seligman et al., 2005 y Carr, 2007).

6. La Trascendencia. En esta virtud se encuentran el grupo de fortalezas que conectan o vinculan con el universo o un ser superior y permiten dar sentido a la existencia (Peterson \& Seligman, 2004; Seligman et al., 2005 y Carr, 2007).

Es importante establecer la relación que se da entre las virtudes y las fortalezas de carácter según la Psicología positiva. Esta relación se da de dos formas: por un lado, las virtudes están integradas por una serie de fortalezas -24 en concreto- (Peterson \& Seligman, 2004) y a su vez las fortalezas se pueden ver como las "vías para alcanzar las virtudes" (Carr, 2007, p. 82). Es decir, las 
virtudes están integradas por las fortalezas, y a su vez, estas últimas son los medios por los cuales se alcanzan y acrecientan las virtudes.

En el caso de las fortalezas o fuerzas del carácter -como también se les designa- se pueden entender de dos formas: como los medios para alcanzar y crecer en las virtudes (Carr, 2007) y como los elementos que conforman a las virtudes (Peterson \& Seligman, 2004). Para Seligman (2002) el desarrollo o crecimiento en las virtudes se da por medio de las fortalezas, ya que con las primeras se corre el riesgo de verlas solo de manera abstracta. Por su parte, las fortalezas son más mensurables; es decir, estas últimas son observables, por lo que su desarrollo en el individuo puede ser visible en conductas concretas.

Peterson \& Seligman (2004, p. 29) y Seligman, et al. (2005, p. 411), definen un listado de criterios para la redacción de un sistema de clasificación de virtudes y fortalezas. Esta clasificación de virtudes y fortalezas, conocido como Valores en Acción "Values in Action" (VIA), lo que pretende es enlistar cada una de las seis virtudes con sus respectivas fortalezas. Valores en acción, por tanto, es una forma de designar a las virtudes con su conjunto de fortalezas particulares.

El listado final de criterios para la clasificación de las fortalezas que integran a las seis virtudes es el siguiente (Peterson \& Seligman, 2004):

- Es ubicua (universal): es reconocida por muchas culturas.

- Es satisfactoria: contribuye a la realización individual, a la satisfacción, y a la felicidad ampliamente entendida.

- Es moralmente valiosa: tiene valor por sí misma, y no como medio para alcanzar un fin.

- No disminuye a los demás: eleva a quienes la ven; produce admiración y no envidia.

- Tiene una contraparte desagradable: tiene un antónimo "negativo" obvio.

- Es un rasgo: es una diferencia individual demostrable, generalizable y estable.

- Es medible: ha sido medida por investigadores como una diferencia individual.

- Es distintiva: no es redundante (conceptual o empíricamente) con otras fortalezas del carácter.

- Es parangón: se encuentra encarnada en algunos individuos de manera sorprendente. 
- Se observa en sujetos prodigios: se encuentra de manera precoz en algunos niños o jóvenes.

- Se puede dar una ausencia selectiva: falta totalmente en algunos individuos.

- Se busca institucionalizar: es el blanco deliberado de algunas prácticas y rituales sociales que intentan cultivarla.

Este listado de criterios permitió definir las 24 fortalezas que integran y a su vez apoyan el logro y desarrollo de las seis virtudes.

En este llamado que la Psicología positiva hace para promover investigaciones relacionadas con estos tres conceptos: carácter, virtudes y fortalezas, y a partir de una serie de investigaciones, surgió la propuesta de Peterson \& Seligman (2004), el Values in Action (VIA), y el Values in Action Inventory of Strengths (VIA-IS), los cuales se encuentran descritos y explicados en el libro: Character Strengths and Virtues, a Handbook and Classification. En este manual se puede encontrar la clasificación y descripción de las seis virtudes con sus 24 fortalezas que permiten y apoyan que los seres humanos florezcan (Peterson \& Seligman, 2004 y Seligman et al., 2005).

Uno de los objetivos de dicho trabajo de clasificación de las virtudes y sus fortalezas componentes es proporcionar definiciones operativas, instrumentos y medidas, así como modelos de intervención para cada una de las 24 fortalezas del carácter (Powelski, 2003). Estas definiciones operativas, instrumentos y medidas de las fortalezas, permite a su vez corroborar en qué medida una persona ha alcanzado y desarrollado cada una de las seis virtudes con sus respectivas fortalezas.

En el siguiente cuadro se pueden observar las virtudes organizadas con cada una de las fortalezas de carácter, así como una descripción de ellas (Peterson \& Seligman, 2004, p. 29 y Seligman et al., 2005, p. 412).

\begin{tabular}{c|l|l}
\hline \multicolumn{1}{c|}{ VIRTUD } & \multicolumn{1}{|c}{ FORTALEZAS } & \multicolumn{1}{c}{ DESCRIPCIÓN } \\
\hline \multirow{2}{*}{$\begin{array}{l}\text { 1. Sabiduría } \\
\text { Fortalezas cognitivas }\end{array}$} & 1. Creatividad & Pensar en formas productivas e innovadoras de hacer las cosas \\
\cline { 2 - 3 } & 2. Curiosidad & Tomar interés en todas las experiencias \\
\cline { 2 - 3 } & 3. Juicio o Mente abierta & Pensar y analizar las cosas desde diferentes perspectivas \\
\hline
\end{tabular}




\begin{tabular}{|c|c|c|}
\hline \multirow{2}{*}{$\begin{array}{l}\text { que implican la } \\
\text { adquisición y el uso del } \\
\text { conocimiento }\end{array}$} & 4. Amor al aprendizaje & Dominio de nuevas habilidades, temas y cuerpos de conocimiento \\
\hline & 5. Perspectiva & Ser capaz de dar consejo sabio a los demás \\
\hline \multirow{4}{*}{$\begin{array}{l}\text { 2. Valentía } \\
\text { Fortalezas que implican } \\
\text { el ejercicio de la } \\
\text { voluntad para lograr } \\
\text { metas a pesar de la } \\
\text { oposición }\end{array}$} & 6. Valor o Valentía & $\begin{array}{l}\text { No huir de las amenazas, de los retos, de las dificultades o del } \\
\text { dolor }\end{array}$ \\
\hline & $\begin{array}{l}\text { 7. Honestidad, Autenticidad o } \\
\text { Integridad }\end{array}$ & Hablar con la verdad y presentarse de manera genuina \\
\hline & 8. Perseverancia o Persistencia & Terminar lo que se empieza \\
\hline & 9. Entusiasmo o Vitalidad & Acercarse a la vida con emoción y energía \\
\hline \multirow{3}{*}{$\begin{array}{l}\text { 3. Humanitarismo } \\
\text { Fortalezas } \\
\text { interpersonales }\end{array}$} & 10. Amor & Valorar las relaciones cercanas con los demás \\
\hline & 11. Bondad, Amabilidad o Generosidad & Hacer favores y buenas obras para los demás \\
\hline & 12. Inteligencia social & $\begin{array}{l}\text { Ser consciente de los motivos y los sentimientos propios y de los } \\
\text { demás }\end{array}$ \\
\hline \multirow{3}{*}{$\begin{array}{l}\text { 4. Justicia } \\
\text { Fortalezas cívicas que } \\
\text { subyacen una vida } \\
\text { comunitaria saludable }\end{array}$} & 13. Trabajo en equipo & Trabajar bien como miembro de un grupo o equipo \\
\hline & 14. Equidad o Responsabilidad social & $\begin{array}{l}\text { Tratar a todos de la misma manera según las nociones de la } \\
\text { equidad y de justicia }\end{array}$ \\
\hline & 15. Liderazgo & Organizar actividades grupales y asegurarse de que se realicen \\
\hline \multirow{4}{*}{$\begin{array}{l}\text { 5. Templanza } \\
\text { Fortalezas que } \\
\text { protegen contra los } \\
\text { excesos }\end{array}$} & 16. Perdón, Misericordia o Compasión & Perdonar a los que nos han hecho mal \\
\hline & 17. Humildad o Modestia & Dejar que los logros hablen por sí mismos \\
\hline & 18. Autorregulación o Autocontrol & Regular lo que uno siente y hace \\
\hline & 19. Prudencia & $\begin{array}{l}\text { Cuidar las opciones, no decir o hacer cosas de las que luego nos } \\
\text { arrepentiremos }\end{array}$ \\
\hline \multirow{5}{*}{$\begin{array}{l}\text { 6. Trascendencia } \\
\text { Fortalezas que forjan } \\
\text { conexiones con un } \\
\text { universo mayor, que } \\
\text { dan sentido }\end{array}$} & $\begin{array}{l}\text { 20. Apreciación de la belleza y la } \\
\text { excelencia }\end{array}$ & $\begin{array}{l}\text { Notar y apreciar la belleza, la excelencia y/o el desempeño } \\
\text { habilidoso en todos los dominios de la vida }\end{array}$ \\
\hline & 21. Gratitud & $\begin{array}{l}\text { Estar consciente de y agradecer todas las cosas buenas que } \\
\text { suceden }\end{array}$ \\
\hline & 22. Esperanza u Optimismo & Esperar lo mejor y trabajar para lograrlo \\
\hline & 23. Humor o Alegría & El gusto por la risa y el juego, hacer sonreír a los demás \\
\hline & 24. Espiritualidad o Religiosidad & $\begin{array}{l}\text { Tener creencias coherentes sobre el fin último y el significado de la } \\
\text { vida }\end{array}$ \\
\hline
\end{tabular}

Cuadro 1: Las virtudes con sus fortalezas. Retomado y adaptado de Seligman (2005); la parte de Aristóteles es nuestra.

La Psicología positiva apoyando acciones relacionadas con el carácter, las virtudes y las fortalezas de carácter ha impulsado una serie de investigaciones, surgiendo de éstas la propuesta de Peterson y Seligman (2004), el Values in Action (VIA), y el Values in Action Inventory of Strengths (VIA-IS), los cuales se encuentran descritos y explicados en el libro: Character Strengths and Virtues, a Handbook and Classification. En este manual se puede encontrar la clasificación y descripción de las seis virtudes con sus 24 fortalezas que permiten y apoyan que los seres humanos florezcan (Peterson y Seligman, 2004 y Seligman et al., 2005). 
Uno de los objetivos de dicho trabajo de clasificación de las virtudes y sus fortalezas componentes es proporcionar definiciones operativas, instrumentos y medidas, así como modelos de intervención para cada una de las 24 fortalezas del carácter (Powelski, 2003). Estas definiciones operativas, instrumentos y medidas de las fortalezas, permite a su vez corroborar en qué medida una persona ha alcanzado y desarrollado cada una de las seis virtudes con sus respectivas fortalezas.

\section{La virtud de la sabiduría en la Psicología positiva}

En particular, la virtud de la sabiduría o conocimiento, como se observa, se define en esta corriente psicológica que estamos analizando, como el conjunto de fortalezas de carácter que ayudan a la adquisición y al uso de los diferentes saberes. Las fortalezas de carácter que integran a esta virtud son: 1. Creatividad, pensar en formas productivas e innovadoras de hacer las cosas; 2 . Curiosidad, tomar interés en todas las experiencias; 3. Juicio o Mente abierta, pensar y analizar las cosas desde diferentes perspectivas; 4. Amor al aprendizaje, dominio de nuevas habilidades, temas y cuerpos de conocimiento; y 5. Perspectiva, ser capaz de dar consejo sabio a los demás (Powelski, 2003 y Peterson \& Seligman, 2004).

Analizando lo anterior desde la perspectiva de Brennan (1969), en su libro Psicología general, hablando sobre la vida intelectual y la mente humana -las cuales se pueden relacionar directamente con la virtud de la sabiduría- afirma que el grado más alto en la escala de conciencia de los seres en el universo lo encontramos en el hombre, ya que éste puede pensar y desear, siendo su producción intelectual la forma de conocimiento más elevada, al mismo tiempo es capaz de elegir y labrar su propia función en el contexto en el que vive.

A diferencia de los seres inferiores a él, éste es capaz de conocer la esencia o naturaleza de las cosas y de él mismo; todo lo anterior le permite edificar un conjunto sistematizado de conocimientos, unificados a partir de su experiencia, lo que le permitirá enfrentarse a las nuevas experiencias con un conocimiento y método previos. Esta capacidad de pensar y de actuar voluntariamente constituirán en gran medida los contenidos de su mente (Brennan, 1969, p. 289). 
Reafirmando lo anterior, Shute (1946), hablando sobre la conducta humana desde la visión aristotélica, afirma que "en el alma racional del hombre, encontramos el pensamiento, que constituye un factor de dominio de la conducta humana" (p. 93). En otras palabras, podemos afirmar que, en el hombre, su conducta o actuar, no está sólo guiado por sus instintos o por su respuesta ante aquellos estímulos exteriores que lo afectan, sino que va más allá, que su raciocinio y su pensamiento le permiten conducirse de manera diferente al animal, sus acciones tendrán la posibilidad de hacerle crecer en conocimientos, habilidades y capacidades, en hacerlo más persona, en crecer en virtudes, y entre éstas en "Sabiduría".

En otras palabras, diríamos, la conformación y desarrollo en el hombre de la virtud de la sabiduría, aquella que le permite adquirir, construir y utilizar los diferentes saberes por medio o apoyándose en las siguientes competencias: en su creatividad, proponiendo y realizando de forma innovadora sus quehaceres; en su curiosidad, inclinándose por buscar nuevas experiencias de aprendizaje; en su juicio o mente abierta para enfrentar y transformar los objetos, sucesos y eventos desde diferentes enfoques; en su amor o gusto por aprender, buscando conocer, construir y dominar nuevas competencias; y en su perspectiva, siendo capaz de compartir con otros aquel conocimiento y competencias que ha desarrollado.

El mismo Brennan (1969, p. 290), reconoce que los actos del pensamiento y la voluntad son difíciles de estudiar, ya que no basta con la observación para poderlos comprender en plenitud. Los procesos vegetativos y las reacciones más simples de los sentidos pueden ser en gran parte medidos por la observación experimental, pero en temas como el juicio, la decisión, el análisis o la conformación de un pensamiento abstracto, el proceso de comprensión se complica grandemente, por ejemplo: La forma como se estudian las percepciones o las emociones o el pensamiento abstracto requieren cada uno de ellos un método de estudio diferente.

Relacionado y apoyando lo anterior, Shute (1946) afirma que "En el hombre, la mente y el deseo, trabajando juntos, producen el movimiento" (p. 100), es decir, en el hombre a diferencia del animal, su actuar inicia por la afectación que le produce el estímulo, esto lo lleva a desear alcanzar o alejarse de dicho estímulo, pero no se queda ahí, en él su actuar va más allá, su mente le permitirá 
tomar caminos mucho más complejos, como el acercarse o buscar aquello que de entrada le desagrada o por el contrario, desear y buscar aquello que en un inicio le desagrada.

\section{Conclusiones}

El objetivo final de este artículo fue determinar qué tanto la visión de la Psicología positiva sobre la virtud de la sabiduría empata con la propuesta por la filosofía realista, en relación a su teoría de las virtudes. Vemos que, pese a la distancia y contextos dispares y lejanos de ambas posturas, el concepto de virtud y sus partes (virtudes particulares) en esencia se mantiene en concordancia.

La resultante de ambas teorías es la felicidad entendida como una consecución natural de las virtudes (Montoya \& Conill, 1988, pp. 126-142), y dentro de su ordenamiento de cara a la vida de los individuos representa un bien y un fin tanto personal como social. Aquí, la virtud de la sabiduría, resume de algún modo a todas las demás, y permite saber cuál elegir en determinada situación y contexto.

Pese a los giros de expresión idiomática y a los marcos teóricos y metodológicos en cada caso, las categorías del corpus ethicum del Estagirita renacen indirectamente en la Psicología positiva de Seligman y otros autores, pues sus coincidencias parecen estar en el fondo y no en la forma. Tanto desde una perspectiva conductual o una perspectiva ética, las virtudes hacen la diferencia en la vida de las personas entre el desarrollo que requieren para llegar al bien que les es propio.

Independientemente del lugar y jerarquía que la virtud de la sabiduría ocupa en ambas teorías, su prioridad es manifiesta en cuanto virtud rectora que permite a los individuos llegar a la felicidad, pues su presencia es de suyo determinante para el mejor empleo de los recursos con los que cuentan en la vida las personas en concreto. En suma, la inteligencia es la clave determinante del actuar humano, pues es, como dice Aristóteles, lo que nos distingue específicamente de los demás seres vivientes.

En contraste con la filosofía realista, advertimos que la Psicología positiva constituye en parte una propuesta innovadora y renovadora para nuestra actualidad, en cuanto a un lenguaje 
contemporáneo se refiere; pues con una luz nueva y un enfoque puesto en estas nuevas investigaciones parece reclasificar lo que la filosofía clásica aristotélica había propuesto hace más de 2400 años con vigencia perenne, y lo hace bajo una perspectiva modernizada y en diálogo abierto con un enfoque humanista muy completo. $Y$ es que "resulta difícil hacer justicia a esta tesis aristotélica, debido al profundo cambio que ha experimentado la reflexión ética desde Aristóteles hasta nuestros días. Cambio que no es sin duda casual, sino debido a profundas transformaciones políticas, sociales y culturales" (Montoya \& Conill, 1988, p. 143).

\section{Referencias}

Aristóteles. (1996), Ética Nicomaquea, México: Universidad Nacional Autónoma de México. Trad. de Gómez-Robledo, A.

Brennan, R. E. (1969), Psicología general, Madrid: Morata.

Carr, A. (2007), Psicología positiva, Barcelona, España: Paidós Ibérica.

Farre, L. (1982), Heráclito. Fragmentos, Buenos Aires, Argentina: Aguilar.

Gómez-Robledo, A. (2001), "Ensayo sobre las virtudes intelectuales" \& "La sabiduría en Aristóteles", Obras, México: El Colegio Nacional, Vol. 1, pp. 319-347, 376-411.

Lee, A., Steen, T. \& Seligman, M. (2005), "Positive Psychology in Clinical Practice”, The Annual Review of Clinical Psychology, 1, 629-651.

Montoya, J. \& Conill, J. (1988), Aristóteles: Sabiduría y felicidad, Bogotá, Colombia: Cincel Kapelusz. Powelski, J. (2003), "The promise of Positive Psychology for the assessment of character", Journal of College and Character, 4(6) (s/p).

Peterson, C. \& Seligman, M. (2004), Character Strengths and Virtues: A Handbook and Classification, USA: Oxford University Press, Incorporated, Cary, NC.

Rodríguez, Á. (2010), Ética general, Navarra, España: EUNSA.

Seligman, M. (2002), La auténtica felicidad, Barcelona, España: Byblos.

Seligman, M., Steen, T., Park, N. \& Peterson, C. (2005). “Positive Psychology Progress, Empirical validation of interventions", American Psychologist, 60(5), 410-421. 
Shute, C. (1946), La psicología de Aristóteles, Puebla, México: Ed. José M. Cajica Jrzx .

Valenzuela, R. (2014), La phrónesis en la política: Orígenes del concepto aristotélico de prudencia, Guadalajara, México: Universidad de Guadalajara. 